water, and filter into a Coplin jar which is kept in a $70^{\circ} \mathrm{C}$ incubator. Stain the slide for three minutes at $70^{\circ} \mathrm{C}$.

If the stain is too intense $70 \%$ ethyl alcohol may be used for differentiation.

\section{ULTRATHIN SECTIONING}

Ultrathin sections are made in the usual manner. The wrinkles formed in ultrathin sections during the cutting stage are removed with chloroform vapour as the sections float on the surface of the water. During the flattening process the interference colour of the sections alters to make the sections appear thinner. In view of this apparent change of thickness ultrathin sections are cut slightly thicker than required.

The alcoholic uranyl acetate used to stain sections made from Spurr resin frequently removes the sections from the grid. To stop this from happening grids are held in watchmaker's forceps, sprayed with Inhibisol from an aerosol spray (Penetone Co), ${ }^{2}$ and allowed to dry. The grid is then dipped into a dilute solution of wetting agent (eg, Teepol in distilled water) and used immediately. The wetting agent reduces the surface tension of the water which would normally cause the sections to slip off the grid.

Ultrathin sections are stained as follows: (1) Stain the sections in 5\% uranyl acetate in methanol for five minutes. Use a covered staining well to prevent evaporation of the methanol.

(2) Wash the grid in methanol and allow to dry.

(3) Stain in Reynold's lead citrate for five minutes.

(4) Wash in distilled water and allow to dry in a dust-free atmosphere.

The grid is now ready for examination in the electron microscope.

\section{Results}

Using the methods described we now embed a wide range of human and animal tissue in Spurr resin. Blocks from this resin are considerably easier to section than epon and ultrathin sections of high quality are routinely obtained.

We wish to thank Miss Maureen Paterson and Dr M. A. Woodhouse for their assistance.

References

Luft, J. H. (1961). Improvements in epoxy resin embedding methods. J. biophys. biochem. Cytol., 9, 409-414.

Spurr, A. R. (1969). A low-viscosity epoxy resin embedding medium for electron microscopy. J. ulrastruct. Res., 26, 31-43.

'Inhibisol spray, Penetone Co Ltd, Cramlington, Northumberland, England.

\section{A method for preparing and staining the platelet-collagen interaction for microscopic observation}

R. J. THOMPSON AND R. D. MACKENZIE From the Biochemistry Department, Merrell-National Laboratories, Division of Richardson-Merrell Inc, Cincinnati, Ohio, USA

Interactions in vivo involving circulating platelets and subintimal collagen have been reported to be fundamental in the formation of a thrombus (Hovig, Jorgensen, Packham, and Mustard, 1968). Most microscopic investigations concerning the adhesion of platelets to collagen employ in-vivo methods, such as histological examination of exposed intimal collagen and adhering platelets after induced arterial trauma (Warren, 1971). In contrast to in-vivo methods this in-vitro method offers a controlled procedure for preparing and differentially staining the plateletcollagen interaction. This procedure makes possible the investigation of different parameters affecting both platelet-collagen adhesion and the aggregation of free platelets to collagen-adhering platelets.

\section{Methods}

A $0.1 \mathrm{ml}$ aliquot of human tendon suspension, prepared according to Hovig (1963), is added to $1.0 \mathrm{ml}$ of human platelet-rich plasma, obtained by the method of MacKenzie, Blohm, and Auxier (1971). The suspension is gently agitated for three seconds, and, at the fifth second, the interaction between platelets and collagen is stopped by the addition of $3.0 \mathrm{ml}$ of $4 / 3 \%$ glutaraldehyde solution. Centrifugation at $90 \mathrm{~g}$ for 10 minutes precipitates the platelet-collagen masses from the suspension. The supernatant is discarded, $3.0 \mathrm{ml}$ of Tyrode's solution added to the precipitate, and the mixture gently agitated. After 20 minutes the suspension is centrifuged for 10 minutes at $90 \mathrm{~g}$, the supernatant discarded, and the platelet-collagen masses are resuspended in $1 \mathrm{ml}$ of Tyrode's solution. A slide smear is prepared with two drops of the suspension, and allowed to dry in air.

After the slide is dry, it is fixed for 2.5 minutes in the glutaraldehyde-ethanol fixative, rinsed in distilled water, and stained by the following sequence.

1 Stain in the acid fuchsin-sirius red stain for 20 minutes.

2 Stain in $25 \%$ Wright's stain (in distilled water) for five minutes.

Received for publication 31 July 1972. 
3 Stain in Masson's fast green stain for $7.5 \mathrm{~min}$ utes.

After each stain the slide is rinsed in fresh distilled water, the stain set for one minute in $0.5 \% \mathrm{HCl}$, and the slide again rinsed. The slide is air dried after the staining process is complete, and microscopically observed.

\section{Preparative Solutions (Brinkhous, 1971)}

\section{$4 / 3 \%$ GLUTARALDEHYDE SOLUTION}

1 Distilled water $\quad$. $\quad \ldots \quad \ldots \quad 116.8 \mathrm{ml}$

$28 \%$ glutaraldehyde $\quad \ldots \quad \ldots \quad \ldots \quad \ldots \quad 40.0 \mathrm{ml}$

$30.28 \mathrm{M}$ veronal acetate buffer $\quad \ldots \quad 32.0 \mathrm{ml}$

$4 \mathrm{HCl}(0 \cdot 2 \mathrm{~N}), p \mathrm{H}$ to $7 \cdot 4-7 \cdot 6$

5 Distilled water to final volume of $\quad . \quad 250.0 \mathrm{ml}$

TYRODE'S SOLUTION

\begin{tabular}{|c|c|c|c|c|c|c|}
\hline $\mathrm{NaCl}$ & $\cdots$ & $\cdots$ & $\cdots$ & • & $\cdots$ & $4.0 \mathrm{~g}$ \\
\hline $\mathrm{KCl}$ & . & .. & $\cdots$ & $\cdots$ & . & $0 \cdot 1$ \\
\hline $\mathrm{CaCl}_{2}$ & $\ldots$ & . & . & $\cdots$ & $\cdots$ & 0.05 \\
\hline $\mathrm{NaHCO}$ & & . & $\cdots$ & $\cdots$ & $\cdots$ & $0.5 \mathrm{~g}$ \\
\hline $\mathrm{MgCl}_{2}$ & $\cdots$ & . & . & . & $\cdots$ & 0.05 \\
\hline $\mathrm{NaH}_{2} \mathrm{PO}$ & & $\ddot{\text { to }}$ & $\ddot{f}$ & volu & of & $\begin{array}{l}0.025 \\
250 \mathrm{r}\end{array}$ \\
\hline
\end{tabular}

\section{Staining Solutions}

GLUTARALDEHYDE-ETHANOL FIXATIVE

$14 / 3 \%$ glutaraldehyde solution. . . . $20.0 \mathrm{ml}$

2 Absolute ethanol $\quad \ldots \quad$.. $\quad \ldots \quad 20.0 \mathrm{ml}$

3 Distilled water to make final volume .. $\quad 100.0 \mathrm{ml}$

ACID FUCHSIN-SIRIUS RED F3BA STAIN

1 Acid fuchsin $\ldots \quad \ldots \quad \ldots .03 \mathrm{~g}$

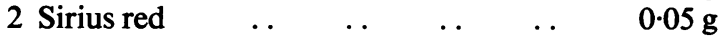

3 Saturated aqueous picric acid $\quad \ldots \quad 100.0 \mathrm{ml}$

4 Concentrated $\mathrm{HCl}$ to $\mathrm{pH} 1 \cdot 3$

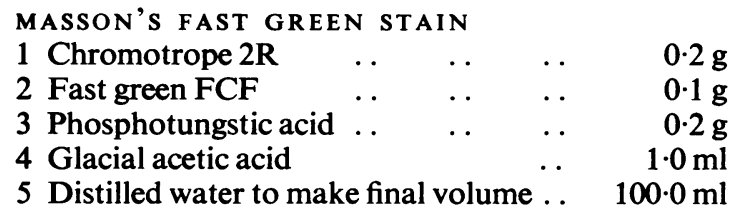

\section{Results and Comment}

With this staining procedure, platelets appear reddish purple and collagen blue (Fig.). Alterations in platelet colour may be achieved by varying the staining time in the acid fuchsin-sirius red F3BA stain, although variations in collagen colour are difficult to obtain. The Masson's fast green stain is used to intensify the colour of both platelets and

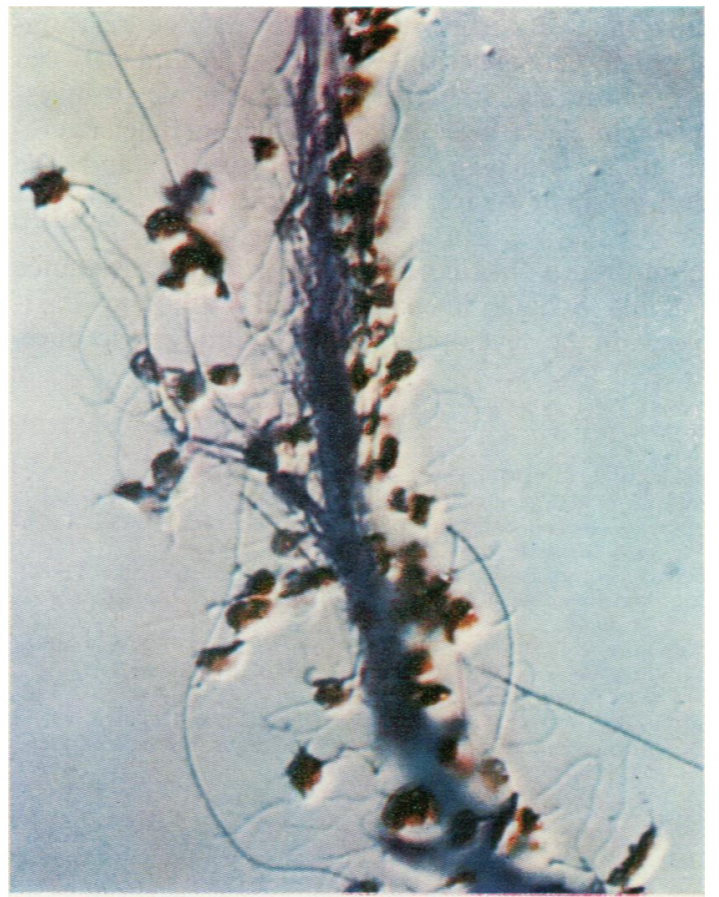

Fig. Platelet-collagen interaction. Photomicrograph taken in partial Nomarski interference using a Leitz Orthoplan microscope. $\times 5000$

collagen, but is not responsible for staining either one.

Collagen, when prepared by this method, assumes several different morphological forms, relatively large fibres, small fibrils, and mesh-like networks of fibrils. When platelet-collagen masses are microscopically observed, smaller collagen fibrils are difficult to recognize, for their mass is not sufficient to transmit adequate colour. By using an interferencebright field system and higher magnifications, these fibrils are detectable. Observation of these small fibrils is essential when attempting to distinguish adhesion from aggregation to adhering platelets.

Adhesion is instantaneous when platelets and collagen are exposed to one another; agitation is used only to promote the incidence of interaction. Progressive degrees of adhesion are observed if the agitation time is varied from zero to three to five seconds, and the fixing time remains constant at five seconds. With the agitation time constant at three seconds, various fixing times of five, 15, and 30 seconds yield increasing degrees of aggregation to collagen-adhering platelets. Therefore, the degree of adhesion is dependent on the amount of agitation, and the degree of aggregation is dependent on the 
fixing time. By using the time-orientated relationships between adhesion and agitation and between aggregation and fixing time, it is possible to investigate platelet adhesion to collagen, platelet aggregation to collagen adhering platelets, and the relationship of the two.

The authors would like to acknowledge the assistance of Viola Schnell, Department of Pathology-Toxicology, in the development of the staining procedure.

References

Brinkhous, K. M.(1971). Personal communication

Hovig, T. (1963). Aggregation of rabbit blood platelets produced in vitro by saline 'extract' of tendons. Thrombos. Diathes. haemorrh. (Stuttg.), 9, 248-256.

Hovig, T., Jorgensen, L., Packham, M. A., and Mustard, J. F. (1968). Platelet adherence to fibrin and collagen. J. Lab. clin. Med., 71, 29-40.

MacKenzie, R.D., Blohm, T. R., and Auxier, E. M. (1971). A modified Stypven test for the determination of platelet factor 3. Amer.J. clin. Path., 55, 551-554.

Warren, B. A. (1971). The platelet pseudopodium and its involvement in aggregation and adhesion to vessel walls. Brit.J. exp. Path., 52, 378-387.

\section{A comparison of serum folate estimations using two different methods}

J. D. O'BROIN, J. M. SCOTT, AND I. J. TEMPERLEY From the Haematology Laboratory, Federated Dublin Voluntary Hospitals, and Departments of Clinical Medicine and Biochemistry, Trinity College, Dublin

Most service laboratories have followed the method of Waters and Mollin (1961) for the routine estimation of serum folate. Herbert (1966) developed an 'aseptic' technique which obviated protein precipitation and sterilization necessary in the routine method but involved instead the collection of sterile serum. Recently a chloramphenicol-resistant strain of Lactobacillus casei has been developed for use in a fully automated system (Davis, Nicol, and Kelly, 1970). We report a comparison of serum folate results using a routine and a simple semi-automated 'chloramphenicol' method.

\section{Methods}

'CHLORAMPHENICOL' SERUM FOLATE ASSAY Stock cultures of a chloramphenicol-resistant strain of $L$. casei (NCIB 10463) were stored at $4^{\circ} \mathrm{C}$ in sterile lactobacillus broth AOAC (Difco) containing $100 \mu \mathrm{g} / \mathrm{ml}$ chloramphenicol BP. Twenty-four hours before assay the stock culture was subcultured into lactobacillus broth containing $10 \mu \mathrm{g} / \mathrm{ml}$ chloramphenicol. A dilute suspension of the washed organism was added to the cooled bulk medium.

On the day of assay, using micropipettes, 30 and $50 \mu \mathrm{l}$ serum were each added to two tubes containing $4.0 \mathrm{ml}$ half-strength inoculated BBL assay medium which contained $50 \mu \mathrm{g} / 100 \mathrm{ml}$ ascorbic acid and $1.0 \mathrm{mg} / 100 \mathrm{ml}$ chloramphenicol. Using micropipettes $0,10,20,40,60,80$, and $100 \mu l(0 \cdot 0-0 \cdot 5 \mathrm{ng})$ of the final standard folic acid solution were added to assay tubes in quadruplicate. The tubes containing standards and sera were incubated for $\mathbf{4 2}$ hours. The optical density was read using a Vitatron automated digital colorimeter.

ROUTINE AUTOCLAVING METHOD

The routine autoclaving method (Waters and Mollin, 1961) was used for comparison.

\section{Results}

Using the 'chloramphenicol' method serum folate levels estimated in 80 blood donors ranged from 2.5 to $14.0 \mathrm{ng} / \mathrm{ml}$ with a mean of $6 \cdot 3 \mathrm{ng} / \mathrm{ml}$. Fourteen Received for publication 17 August 1972. 